\title{
High Throughput In Situ XAFS Screening of Catalysts
}

\author{
Nikolaos Tsapatsaris, ${ }^{1}$ Angela M. Beesley, ${ }^{1}$ Norbert Weiher, ${ }^{1}$ Helen Tatton, ${ }^{1}$ Andy \\ J. Dent, ${ }^{2}$ Frederick J.W. Mosselmans, ${ }^{2}$ Moniek Tromp, ${ }^{3}$ Sergio Russu, ${ }^{3}$ John \\ Evans, ${ }^{2,3}$ Ian Harvey, ${ }^{4}$ Shu Hayama, ${ }^{4}$ Sven L.M. Schroeder, ${ }^{*}$
}

\author{
${ }^{I}$ The University of Manchester, Molecular Materials Centre, School of Chemical Engineering and Analytical \\ Science \& School of Chemistry, Manchester, M60 1QD, PO Box 88, UK; ${ }^{2}$ Diamond Light Source, Chilton, Didcot, \\ OX12 OQX, UK, ${ }^{3}$ University of Southampton, School of Chemistry, Southampton, SO17 1BJ, United Kingdom; \\ ${ }^{4}$ CCRLC Daresbury Laboratory, Warrington, Cheshire, WA4 4AD, UK
}

\begin{abstract}
We outline and demonstrate the feasibility of high-throughput (HT) in situ XAFS for synchrotron radiation studies. An XAS data acquisition and control system for the analysis of dynamic materials libraries under control of temperature and gaseous environments has been developed. The system is compatible with the 96-well industry standard and coupled to multi-stream quadrupole mass spectrometry (QMS) analysis of reactor effluents. An automated analytical workflow generates data quickly compared to traditional individual spectrum acquisition and analyses them in quasi-real time using an HT data analysis tool based on IFFEFIT. The system was used for the automated characterization of a library of 91 catalyst precursors containing ternary combinations of $\mathrm{Cu}, \mathrm{Pt}$, and $\mathrm{Au}$ on $\gamma-\mathrm{Al}_{2} \mathrm{O}_{3}$, and for the in situ characterization of Au catalysts supported on $\mathrm{Al}_{2} \mathrm{O}_{3}$ and $\mathrm{TiO}_{2}$.
\end{abstract}

Keywords: High throughput, XAS, XANES, EXAFS, catalysis.

PACS: $61.10 . \mathrm{Ht}, 81.16 . \mathrm{Hc}, 82.65 .-\mathrm{s}$.

\section{INTRODUCTION}

The development of intelligent and modular instrumentation is imperative for the identification of catalysts and materials with new target functionalities. Integration of many analytical techniques under a single high throughput (HT) experiment enables detailed screening of numerous candidates and reduces the time scale of the experiments [1]. Parallel experimentation increases the probability of significant discoveries by revealing trends in complex data sets. It increases efficiency and allows for significant reduction of research costs. HT methods have recently become more accepted in the catalytic community, with combinatorial experimentation a promising research avenue for the discovery of new catalysts and optimization of their yield and selectivity [2-4]. Besides measurements of reaction kinetics, spectroscopic methods such as infrared spectroscopy [5], Raman spectroscopy [6], X-ray fluorescence [7], fluorescence microscopy [8], imaging polarimetry [9], nuclear magnetic resonance spectroscopy [10] and Xray diffraction [11] have been incorporated in highthroughput instrumentation. These techniques are valuable for characterizing large sample libraries but have limitations, e.g. difficulties with in situ realization (nuclear magnetic resonance) or the restriction to crystalline materials (X-ray diffraction). The flexibility and inherent advantages of X-ray absorption spectroscopy (XAS) for non-crystalline systems have not been utilized in HT research and present new and promising research ground [13].

\section{EXPERIMENTAL}

The HT XAS data acquisition and control system comprises a high-precision positioning stage $(x, y, z, \theta)$ that allows positioning of highly compact arrays (more than 1000 discrete materials $/ \mathrm{cm}^{2}$ ). For the in situ experiments a custom-made 8-fold microreactor array was used. Individual gas flows are supplied via independent mass flow controllers (MFCs); the effluent of each cell is monitored by quadrupole mass spectrometry (QMS), Fig. 1.

XAS experiments were carried out at station 9.3 of the SRS in Daresbury, UK [15]. The HT EXAFS analysis was performed using Linux shell scripts that, sequentially, (i) read all the spectra produced, (ii) applied the IFEFFIT background subtraction routine and (iii) performed a single-shell fitting analysis assuming the presence of metal chlorides. Theoretical

CP882, X-ray Absorption Fine Structure - XAFS13

edited by B. Hedman and P. Pianetta

(C) 2007 American Institute of Physics 978-0-7354-0384-0/07/\$23.00 
amplitudes and phase functions used in the fitting procedure were calculated with FEFF6 [16]. All the fits were performed using multiple k-weightings of 1 , 2 and 3. The fitting algorithm required the input of initial guess values for backscattering species, edgeposition, coordination number $(N)$ nearest neighbor distance $(R)$ and Debye-Waller factor $\left(\sigma^{2}\right)$. The script then reports back with the shift on the edge position, the edge-step (ES) values, the normalized data, the $\chi(\mathrm{k})$ data, the Fourier transformed data, the fitted EXAFS curves and the resulting fitted values for $N, R$ and $\sigma^{2}$. This software performed single-shell EXAFS analysis on 96 samples at two different edges (i.e., a total of 192 spectra) in approximately 15 minutes.
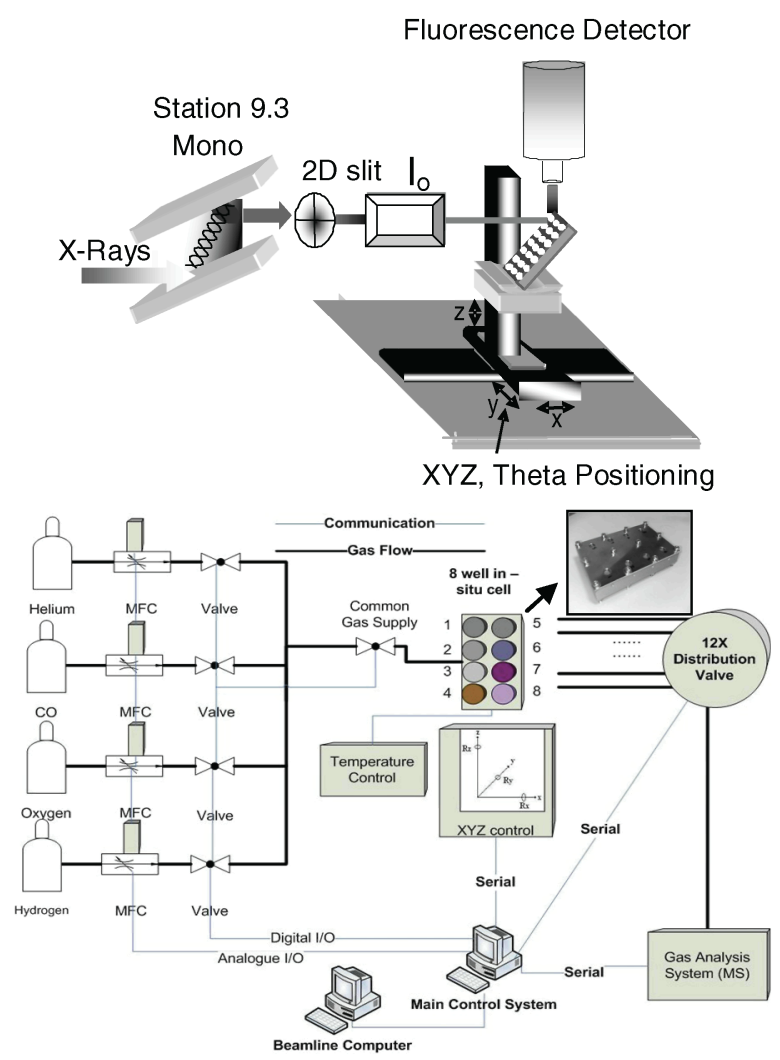

FIGURE 1. HT XAFS instrumentation in Station 9.3 of SRS Daresbury. Top: Placement of robotic stage with respect to detector and X-ray beam. Bottom: Main system components and communication interface with beamline. The inset shows the custom made $8 \mathrm{x}$ reactor.

Experiments with the 96-wellplate were conducted using catalyst precursors prepared by wet impregnation of a $\gamma-\mathrm{Al}_{2} \mathrm{O}_{3}$ (D1011, BASF) support (200-450 $\mu \mathrm{m}$ particle size) with solutions of $\mathrm{CuCl}_{2}$ (Aldrich, 99.995\%), $\mathrm{PtCl}_{2}$ (Aldrich, 98\%) and $\mathrm{HAuCl}_{4}$ (Riedel-de Haën, 51\% Au) in concentrated $\mathrm{HCl}$. A standard glass 96 well plate was used to prepare and store the samples. The library comprises of permutations of $\mathrm{Cu}, \mathrm{Pt}$ and $\mathrm{Au}$ in concentrations of $\mathrm{O}$,
$0.1,1$ and 5 wt $\%$ resulting in a library of 91 elements. Figure $2 \mathrm{a}$ shows the $\mathrm{Cu}$ concentration in wt $\%$ for each of the library members. CO oxidation in situ experiments utilized catalysts of different concentrations of $\mathrm{Au} / \mathrm{TiO}_{2}$ and $\mathrm{Au} / \mathrm{Al}_{2} \mathrm{O}_{3}$ and were prepared by a modified incipient method as described in [14].

\section{RESULTS \& DISCUSSION}

Some of the results from the ex situ HT-XAS analysis of spectra taken at the $\mathrm{Cu} \mathrm{K}$-edge are shown in Figs. 2. It presents the $\mathrm{Cu}$ concentration in the catalysts (Fig. 2a) and the determined number $N$ of coordinating $\mathrm{Cl}$ atoms (Fig. 2b). Black color in the figures indicates either the absence of the metal under study or spectra not analysed because of an extremely low $\mathrm{S} / \mathrm{N}$ ratio. The usefulness of these visual maps shall be illustrated using an example. The $N$ map (Fig. 2b) has an 'island' of samples (E6, F6 and G6) with very low $\mathrm{Cl}$-coordination numbers, which are clearly non-sensical. The EXAFS from these samples were thus further examined individually.

The analysis, somewhat unexpectedly, revealed the presence of $\mathrm{Cu}$ metal in these samples. The plausibility of this result is underlined by the data presented in Figure 2c, which shows the full XANES spectra of samples A7 and E8 (corresponding essentially to unreacted $\mathrm{CuCl}_{2}$ ), of samples E6, F6, G6 (containing $\mathrm{Cu}$ metal), and of $\mathrm{Cu}$ foil.

$\mathrm{X}$-ray induced reduction of $\mathrm{Cu}^{2+}$ was excluded as it was not observed in any of the other samples. It was noticed, however, that the reduction to $\mathrm{Cu}^{0}$ was limited to samples in which $\mathrm{PtCl}_{2}$ was present. The formation of $\mathrm{Cu}^{0}$ thus appeared to be related to the redox couple
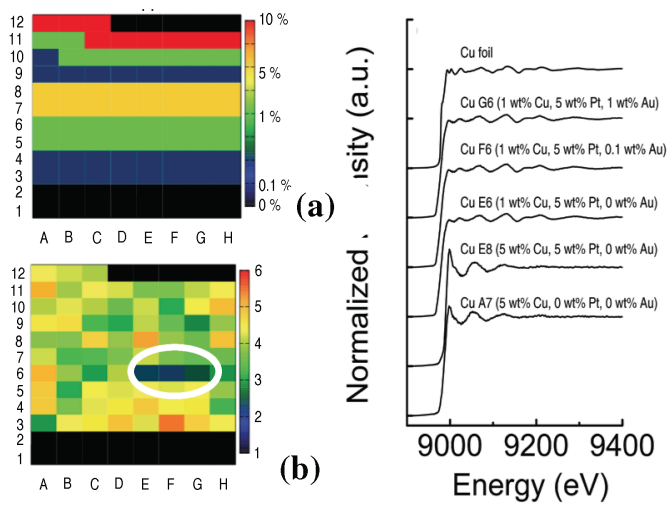

(c)

FIGURE 2. Color map representations of copper concentrations (a) and $\mathrm{Cl}$ coordination numbers (b) for each catalyst precursor, calculated using the script based HT analysis. (c) presents the $\mathrm{Cu} \mathrm{K}$-edge XANES spectra of precursors A7, E8, E6, F6 and G6, and of a Cu metal foil. 


$$
\begin{array}{ll}
{\left[\mathrm{PtCl}_{6}\right]^{2-}+2 \mathrm{e}^{-} \longrightarrow\left[\mathrm{PtCl}_{4}\right]^{2-}+2 \mathrm{Cl}^{-}} & {\left[\mathrm{E}^{0}=+0.68 \mathrm{~V}\right]} \\
\mathrm{Cu}^{2+}+2 \mathrm{e}^{-} \longrightarrow \mathrm{Cu}^{0} & {\left[\mathrm{E}^{0}=+0.34 \mathrm{~V}\right]}
\end{array}
$$

A more quantitative evaluation using the Nernst equation reveals that the reaction

$$
\left[\mathrm{PtCl}_{4}\right]^{2-}+2 \mathrm{Cl}^{-}+\mathrm{Cu}^{2+} \longrightarrow \mathrm{Cu}^{0}+\left[\mathrm{PtCl}_{6}\right]^{2-}
$$

becomes feasible at room temperature in the presence of excess $\mathrm{Cl}^{-}$(note that we used solutions in conc. $\mathrm{HCl})$ and especially during the drying process, which raises the concentrations of all reactants and thus shifts the equilibrium towards the products $\mathrm{Cu}$ metal and $\left[\mathrm{PtCl}_{6}\right]^{2-}$. The expected oxidation of $\mathrm{Pt}^{\mathrm{II}}$ to $\mathrm{Pt}^{\mathrm{IV}}$ was clearly evident also through an increase of the white line in the $\mathrm{Pt}_{3}$-edge XANES from these samples (an example is shown in Fig. 3).

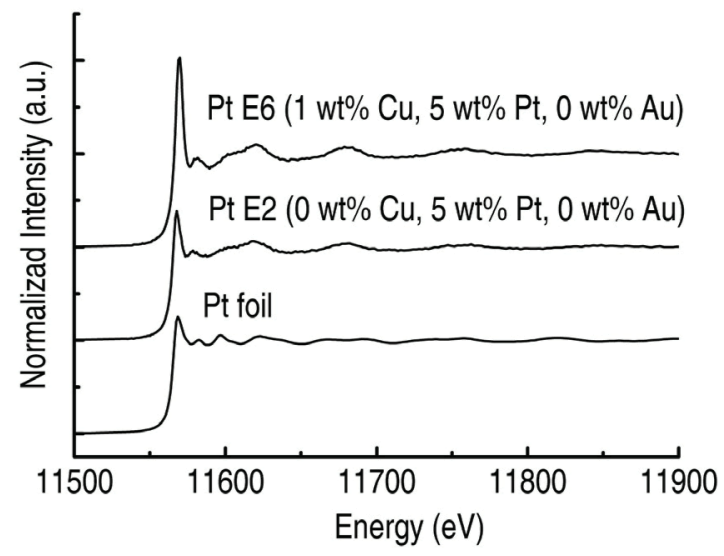

FIGURE 3. $\mathrm{Pt} \mathrm{L}_{3}$-edge XANES spectra of samples E2 (just impregnated with $\mathrm{PtCl}_{2}$ ) and $\mathrm{E} 6$, which contains $\mathrm{Cu}$ metal. Note the strong white line in this sample, indicating the presence of PtIV generated by the reduction of $\mathrm{Cu}^{2+}$.

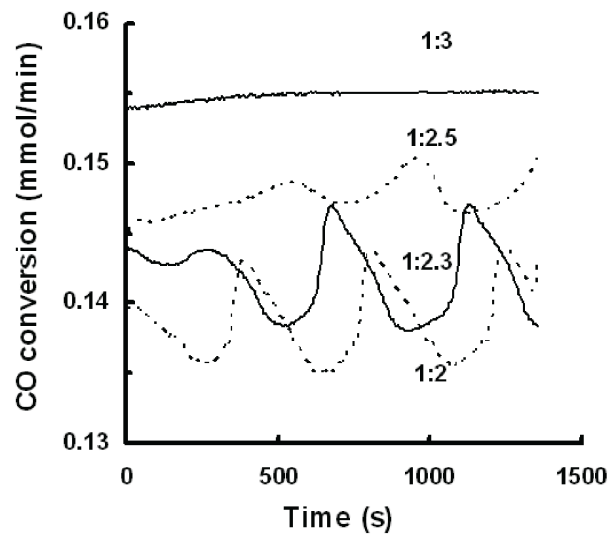

FIGURE 4. Oscillatory $\mathrm{CO}$ conversion over $1 \% \mathrm{Au} / \mathrm{Al}_{2} \mathrm{O}_{3}$ at $\mathrm{CO} / \mathrm{O}_{2}$ ratios between 0.4 and 0.625 .

Finally, illustrating one advantage of HT experimentation, namely serendipitous discovery, is that we found reaction conditions under which rate oscillations occur during $\mathrm{CO}$ oxidation over a number of $\mathrm{Au}$ catalysts (to our knowledge this is the first report of oscillatory $\mathrm{CO}$ oxidation in the field of $\mathrm{Au}$ catalysis). As an example, Fig. 4 shows the rate oscillations over a $1 \% \mathrm{Au} / \mathrm{Al}_{2} \mathrm{O}_{3}$ catalyst. The kinetic oscillations occurred in a 1:2 gas mixture and after a conditioning period of $6 \mathrm{~h}$. Unfortunately, the acquisition of XANES spectra during the experiments was too slow to allow monitoring of the chemical state of the catalyst within one oscillation.

\section{ACKNOWLEDGMENTS}

This work was supported by EPSRC [GR/S85801/01 and GR/S85818/01. We thank the CCLRC SRS at Daresbury for providing beamtime at station 9.3 under award number 44135 .

\section{REFERENCES}

1. R. Hoogenboom, F. Wiesbrock, M A.M. Leenen, M A.R. Meier, U S. Schubert, J. Comb. Chem. 7, 10-13 (2005)

2. R.A. Potyrailo, W.J. Morris, R.J. Wroczynski, P.J. McCloskey, J. Comb. Chem. 9, 869-873 (2004)

3. A. Potyrailo, R. J. Wroczynski, J. P. Lemmon, W. P. Flanagan, O. P. Siclovan, J. Comb. Chem. 5, 8-17 (2003)

4. R. Malhotra, Ed. Combinatorial Approaches to Materials Development; ACS Symposium Series 814 (2002).

5. A. Venimadhav, K.A. Yates, M. G. Blamire, J. Comb. Chem. 7, 85-89 (2005)

6. A. Leugers, D.R. Neithamer, L.S. Sun, J.E. Hetzner, S. Hilty, S. Hong, M. Krause, K. Beyerlein, J. Comb. Chem. 5, 238-244 (2003)

7. T.C. Miller, G. Mann, G.J. Havrilla, C.A. Wells, B.P Warner, T.R. Baker, J. Comb. Chem. 5, 245-252 (2003)

8. M.M. Taniguchi, R.A. Farrer, J. Fourkas, J. Comb. Chem. 7, 54-57 (2005)

9. P.R.Gibbs, C.S. Uehara, P.T. Nguyen, R.C. Willson, Biotechnol. Prog.19, 1329-1334 (2003)

10. R.A. Kautz, W.K Goetzinger, B.L. Karger, J. Comb. Chem. 7, 14-20 (2005)

11. J.H. Reibenspies, N.S.P. Bhuvanesh, J. Pharm. Biomed. Anal. 37, 611-614 (2005)

12. A.E. Russell, A. Rose, Chem. Rev. 104, 4613 (2004)

13. A. Corma, J.M. Serra, P. Serna, M. Moliner, J. Catal. 232, 335 (2005)

14. N. Weiher, E. Bus, L. Delannoy, C. Louis, D.E. Ramaker, J.T. Miller and J.A. van Bokhoven, J. Catal 240, 100-107 (2006).

15. http://www.srs.dl.ac.uk/srs/stations/station9.3.htm.

16. S.I. Zabinsky, J.J. Rehr, A. Ankudinov, R.C. Albers, M. Eller, Phys. Rev. B 52, 2995-3009 (1995).

17. M. Newville, J. Synchrotron Rad 8, 322 (2001). 